\title{
Computational Benchmarks In Simulation Of Cyclic Performance Of Steel Connections Using Three Dimensional Nonlinear Finite Element Method
}

\author{
Mohammad Razavi * Roozbeh Kiamanesh ** Ali Abolmaalii *** \\ * Ph.D. Candidate, CSER Simulation Laboratory, University of Texas at Arlington, USA. \\ ** Ph.D. CSER Simulation Laboratory, University of Texas at Arlington, USA. \\ *** Director, CSER Simulation Laboratory, University of Texas at Arlington, USA.
}

\begin{abstract}
The presented manuscript is intended to introduce accurate computational benchmarks to predict the hysteresis behavior of beam-column steel connections by means of a 3D non-linear finite element analysis. In this study, element type, inelastic material behavior, bolts pre-tensioning, and contact properties between different components of connections are discussed. Incremental nonlinear analysis takes into account all three types of nonlinearities including material, geometry, and contact properties in predicting moment-rotation hysteresis loops. A series of full-scale structural tests are performed to validate the results obtained from the finite element analyses. This study shows that cost efficient numerical analysis simulation is capable of replacing full-scale tests for steel connections.
\end{abstract}

\section{Keywords:}

Connection Modeling, Finite Element Method, Semi-Rigid Connections, Bolted Connections, Moment-Rotation Hysteresis, Nonlinear Dynamic Analysis.

\section{Introduction}

Numerical simulation and finite element method is at its peak of accuracy and capable of simulating the behavior of engineering systems under complex loading. Time consuming and costly full-scale structural testing must be minimized for efficiency. Steel connections are among those whose cyclic testing and finite element modeling have attracted several researchers. This due to the fact that connections are critical ingredients of seismic resistant design and their cyclic behavior directly impact the performance of structures subjected to earthquake vibrations. Steel connections commonly consist of end-plate or angles which are bolted/welded to beam web/flange and bolted or welded to column flange. The combination of bolts and welds has also been used.

Several challenges are involved in numerical modeling of steel bolted connections. Bolted surfaces commonly consist of two plates connected by means of bolts, which are either snug tight (frictionless) or fully pre-tensioned. Bolt pre-tensioning in combination with contact between different surfaces lead to complexity in numerical simulation of semi-rigid connections.

The relationship between the beam end moment versus connection relative rotation (M- $\theta$ ) plays an important role in identifying the ductility and energy dissipation characteristics of bolted or bolted/welded connections. This $M-\theta$ relationship, which is highly sensitive to the connection's geometric variables, can typically be obtained by the 
cost prohibitive full-scale experimental testing (Abolmaali et al. [1]).

Several standardized models ranging from the simplest linear form to bilinear and more complicated polynomial formulas has been fitted to experimental data; however, due to limited parameters used in these models, still there is a need for a reliable tool to produce the moment-rotation curve or moment-rotation hysteresis loops for any arbitrary designed connection.

To eliminate the need for experiments for obtaining static or cyclic $M-\theta$ of connections, nonlinear finite element method can be used as a powerful tool for modeling the cyclic moment-rotation behavior of semi-rigid connections.

Finite element investigations on the behavior of the steel bolted connections started as early as 1976. Majority of the early studied were focused on the correlation of the results from the 2-D models with actual 3D specimen. Computation capability, time dependency of old computers in addition to the substantially high cost of creating and running the 3-D model was the main reason that many researches were conducted in 2-D model. With the advancement of the computer technology, highly sophisticated 3-D models are allowed to be executed without substantial penalties in computation time or cost.

Krishnamurty et al. [2-4] was a pioneer to develop a finite element method for analysis of end-plate connections. This study was limited by the technology of the time. They utilized a 2-D constant strain triangle element and a 3-D eight-node brick element to determine adequate correlation between the results.

Kukreti et al. [5] utilized finite element modeling to develop an equation to characterize the behavior of the extended stiffened end-plate connections. They introduced material nonlinearity by using bilinear material law into the algorithm; however, modeling of contact surfaces was neglected.

Kukreti and Biswas[6] modeled the behavior and failure of end plate connections under cyclic hysteretic loading using the finite element method. The inelastic behavior of the materials was modeled by using incremental plasticity theory described by the Von Mises yield criterion and the Mroz kinematic hardening model.

Kishi et al. [7] studied four finite element models to determine the moment rotation characteristics of the top-and seat-angle with double web angle connections under monotonic loading. Effects of bolt pretension were also considered in the finite element model.

Limited studies are reported with regard to numerical modeling of connection subjected to cyclic loading.

Takhirov and Popov [8] conducted cyclic tests on 48 T-stub test specimens; however, they reported numerical nonlinear analysis of the connection subjected to static loads only.

Nie et al. [9] studied the behavior of three types of steel-concrete composite connection under monotonic and cyclic loading. They reported a fairly good agreement between numerical and experimental study in terms of strength and loading stiffness; however, the reloading stiffness did not match the experimental results and no pinching phenomenon was seen in numerical hysteresis curves because the punching shear failure mode was not accounted in the FEM model.

In this study, essential parameters for modeling bolted connection are presented. Two different contact and friction properties between flat surfaces such as angle/beam and bolt head/beam and also for bolt shank/bolt 
holesandan approach to apply the pre-tensioning bolt force is explained. Since the approach is general it can be applied to any arbitrary bolted connection; however, in order to verify the accuracy of the procedure, five different types of bolted connections are modeled, analyzed, and compared with the experimental test results.

The finite element analyses software package, ABAQUS 6.10-1 is used to create and analyze the numerical models. The beam and column sizes and other geometric parameters of the models are kept identical to the geometry of the specimens used during the experimental testing conducted for this research. Test setup and instrumentations are explained in detail.

\section{Selection of Test Cases}

Five types of semi-rigid with slip critical connections were selected from experimental data conducted by Abolmaali et al. [1] , [10]. These connections include: bolted/bolted double web angle; welded/bolted double web angle; top and seat angle; flush end-plate, and extended end-plate. The geometry of each connection is illustrated in Figures 1 to 5 and geometric values are presented in Table 1.
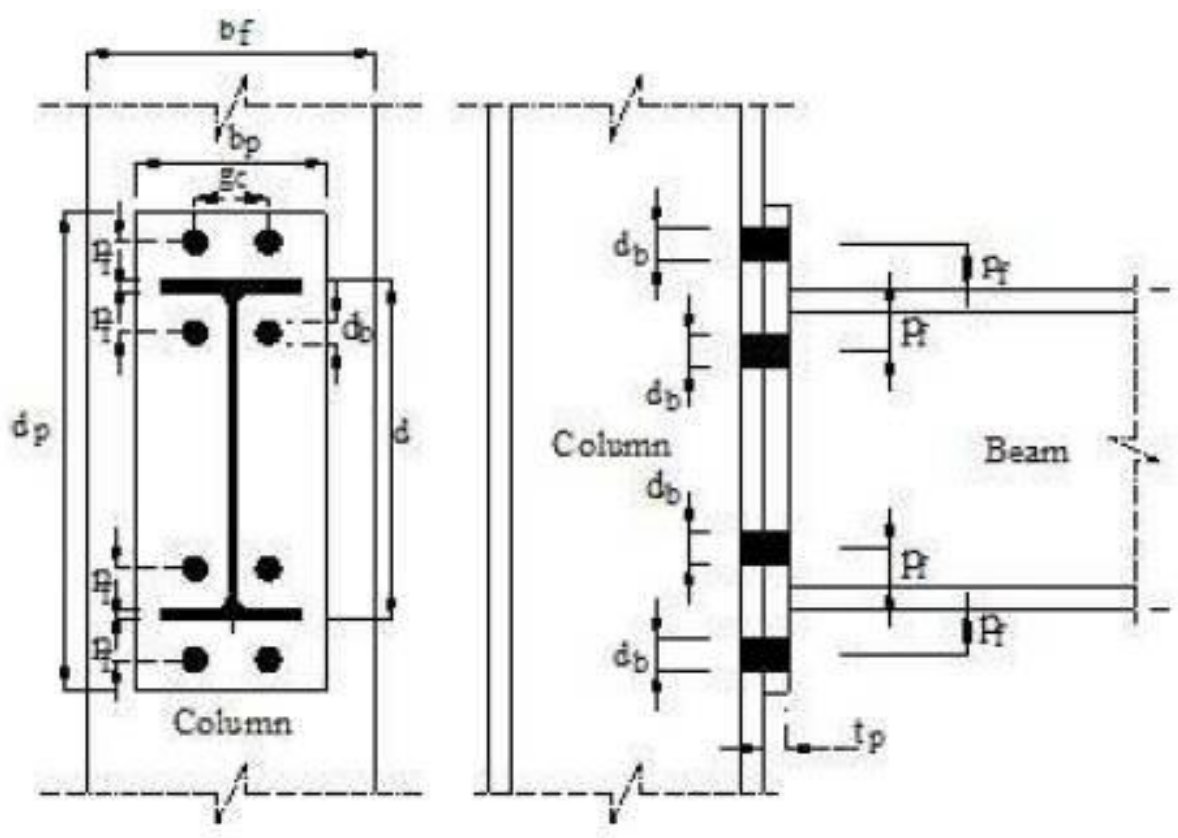

Figure 1. Configuration of Extended End-Plate Connection Test Specimen 


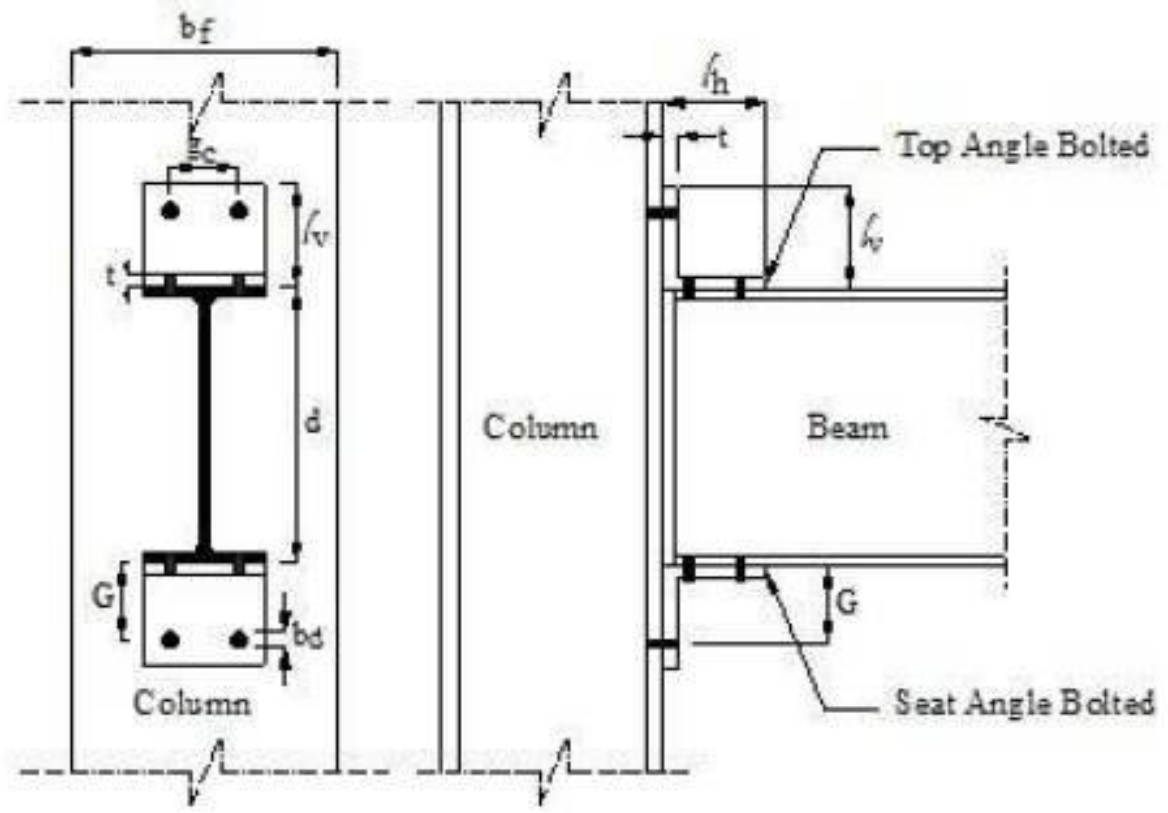

Figure 2. Configuration of Top-and-Seat Connection Test Specimen

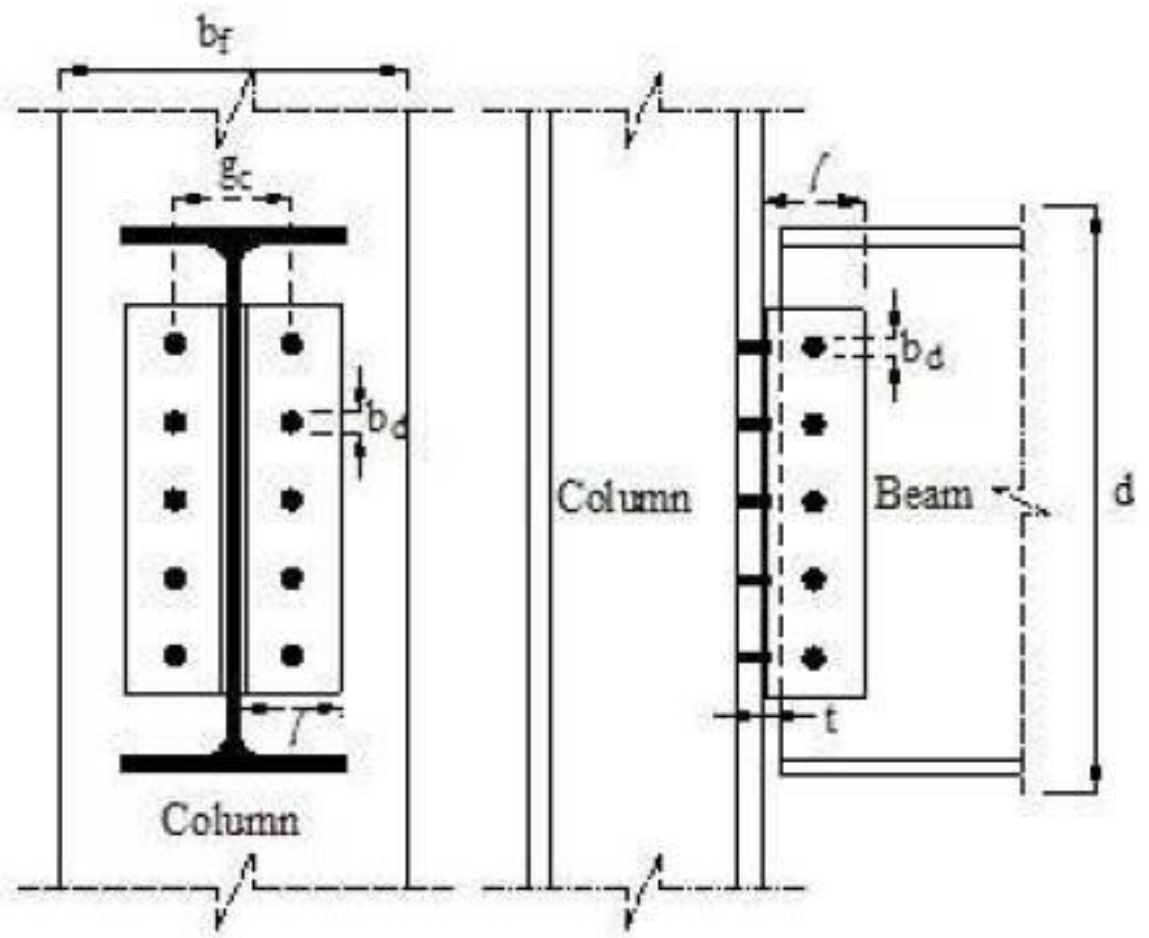

Figure 3. Configuration of Bolted/bolted Double Web Angle Connection Test Specimen 


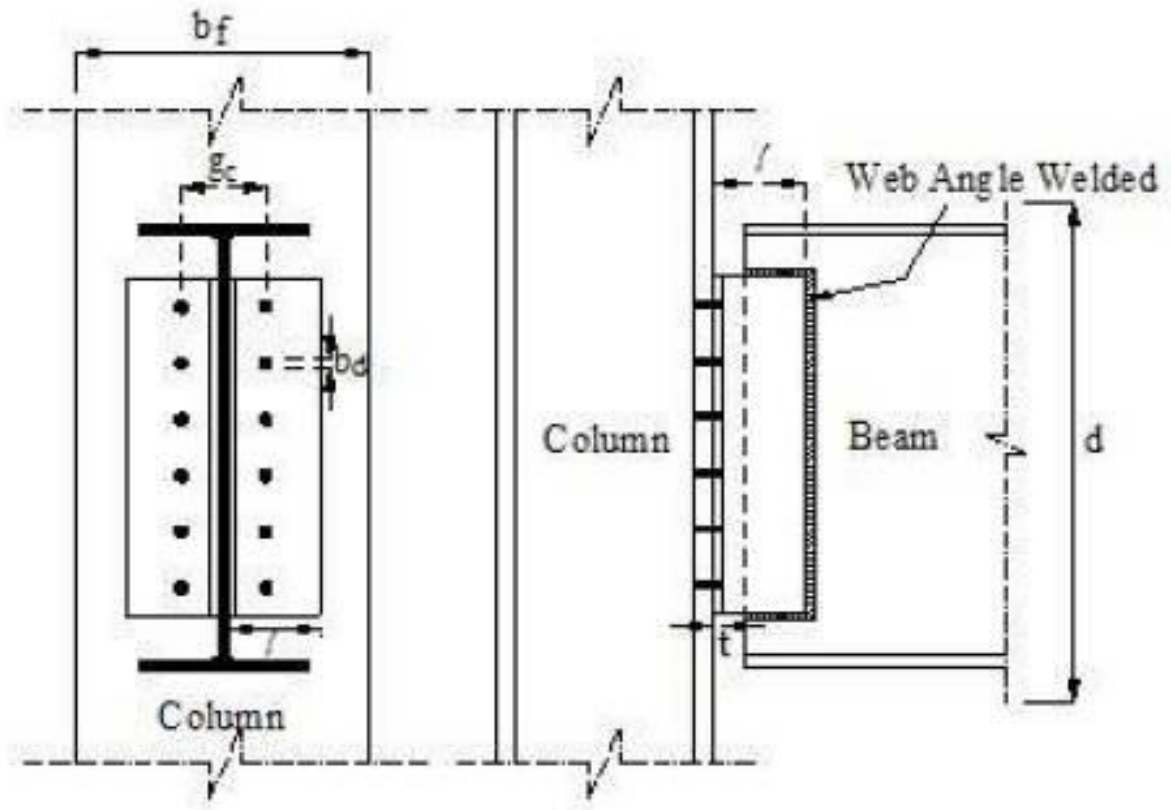

Figure 4. Configuration of Welded/bolted Double Web Angle Connection Test Specimen

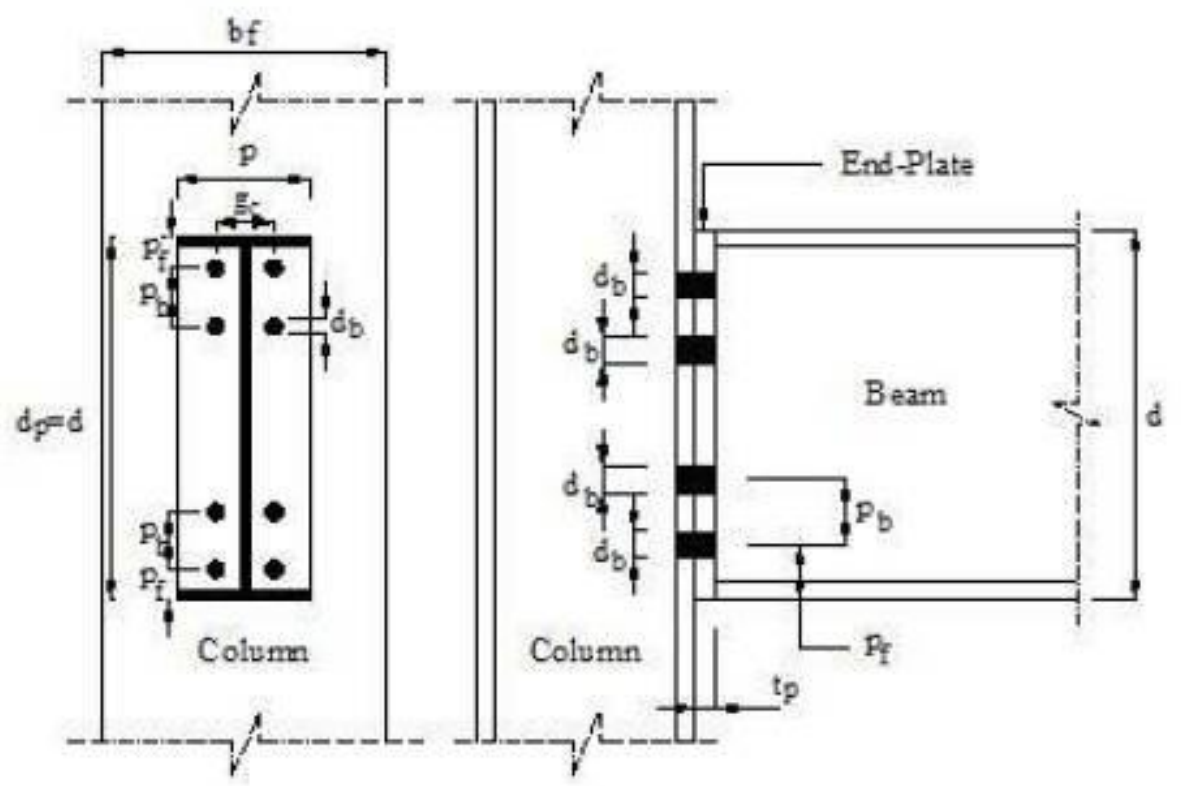

Figure 5. Configuration of Flush End-Plate Test Specimen 


\begin{tabular}{|c|c|c|c|c|c|c|}
\hline \multicolumn{2}{|c|}{ Variable Definition } & \multirow{2}{*}{$\begin{array}{l}\text { Extended } \\
\text { End-Plate } \\
10(254)\end{array}$} & \multirow{2}{*}{$\begin{array}{l}\text { Top-and } \\
\text {-seat }\end{array}$} & \multirow{2}{*}{$\begin{array}{l}\text { Bolted/ } \\
\text { Bolted } \\
\text { Double } \\
\text { Web } \\
\text { Angle } \\
-\end{array}$} & \multirow{2}{*}{$\begin{array}{l}\text { Welded/ } \\
\text { Bolted } \\
\text { Double } \\
\text { Web } \\
\text { Angle } \\
-\end{array}$} & \multirow{2}{*}{$\begin{array}{l}\begin{array}{l}\text { Flush } \\
\text { End- } \\
\text { plate }\end{array} \\
6(152)\end{array}$} \\
\hline$b_{p}$ & End-plate width & & & & & \\
\hline $\mathrm{d}_{\rho}$ & End-plate depth & $22-1 / 2$ & j- & - & - & $18(457)$ \\
\hline$t_{p}$ & $\begin{array}{l}\text { End-plate } \\
\text { thickness }\end{array}$ & $1 / 2(13)$ & - & - & - & $3 / 8(22)$ \\
\hline $\mathrm{b}_{\rho}$ & bolt diameter & $7 / 8(22)$ & $7 / 8(22)$ & $3 / 4(19)$ & $3 / 4(19)$ & $3 / 4(19)$ \\
\hline $\mathrm{N}$ & Number of Bolts & - & - & 5 & 4 & - \\
\hline h & $\begin{array}{l}\text { length of } \\
\text { horizontal angle } \\
\text { legs }\end{array}$ & - & $6(152)$ & $5(127)$ & $5(127)$ & - \\
\hline e & $\begin{array}{l}\text { length of vertical } \\
\text { angle leg }\end{array}$ & & $6(152)$ & - & - & - \\
\hline$t$ & angle thickness & $\cdot$ & $3 / 4$ (19) & $3 / 4$ (19) & $3 / 4(19)$ & $\cdot$ \\
\hline$G$ & $\begin{array}{l}\text { distance from } \\
\text { the heel of the } \\
\text { angle to the } \\
\text { column bolt row }\end{array}$ & - & $2-1 / 2(64)$ & - & - & - \\
\hline pf & $\begin{array}{l}\text { flange pitch, } \\
\text { the distance } \\
\text { from top of the } \\
\text { flange to first } \\
\text { row of bolts }\end{array}$ & $1-3 / 8(35)$ & - & - & - & $5 / 8(41)$ \\
\hline $\mathrm{Pb}$ & $\begin{array}{l}\text { bolt pitch, the } \\
\text { vertical distance } \\
\text { between the } \\
\text { centerline of } \\
\text { bolts of } \\
\text { connection }\end{array}$ & 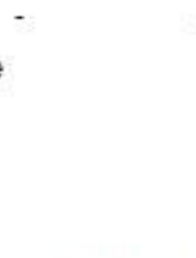 & - & - & - & $3(76)$ \\
\hline$g c$ & $\begin{array}{l}\text { column bolt } \\
\text { gauge }\end{array}$ & $4-1 / 2(114)$ & 4. $(102)$ & $4-1 / 2(114)$ & $\begin{array}{l}5-1 / 2 \\
(140)\end{array}$ & $3(76)$ \\
\hline d & beam depth & $16-5 / 16(414$ & 4) $16(406)$ & $24(610)$ & $24(610)$ & - \\
\hline bf & $\begin{array}{l}\text { column flange } \\
\text { width }\end{array}$ & $15-7 / 8(401)$ & $\begin{array}{l}15-7 / 8 \\
(401)\end{array}$ & - & - & - \\
\hline
\end{tabular}

Table1. Definitions and Geometric Values of Connections. Units are in Inches (mm)

\section{Test Set Up and Instrumentation}

The basic configuration of the test set up used for all types of connections is shown in Figure 6, which consisted of: (i) an actuator to apply the force; (ii) a beam of a reaction frame to support the actuator; and (iii) a column of a reaction frame to support the column in a typical test specimen. The entire reaction frame was bolted to the laboratory floor, and the column of the test specimen was connected to the column of the reaction frame. Lateral 
braces were provided at the beam end connected to the actuator swivel to prevent out-of-plane buckling of the test specimen.

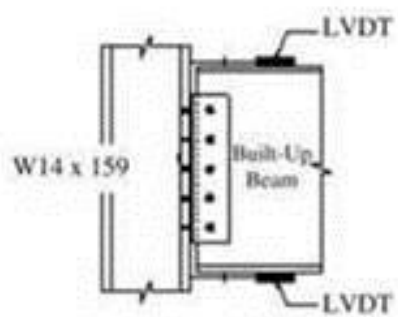

(a) Double angle Connection

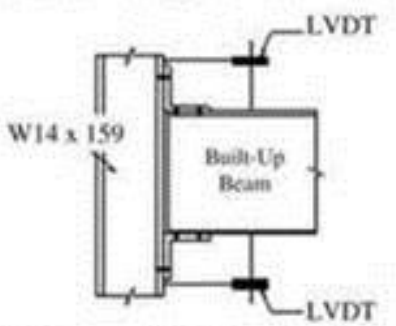

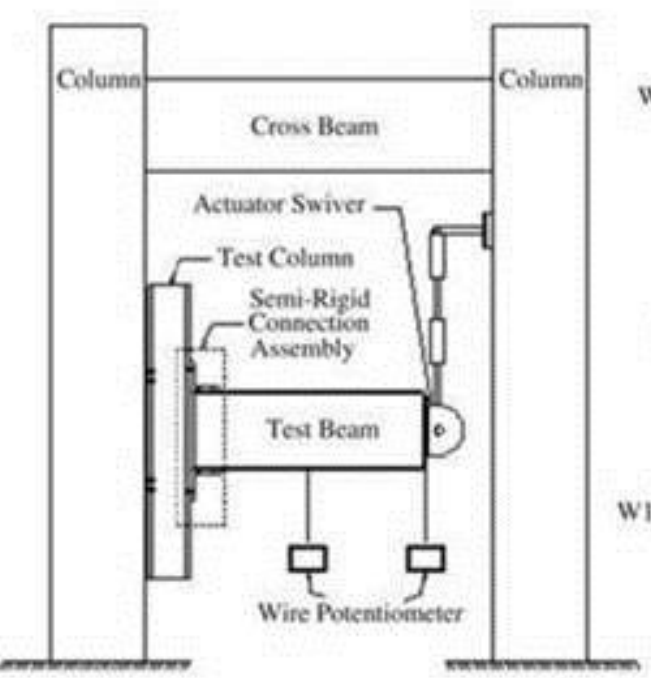

tion

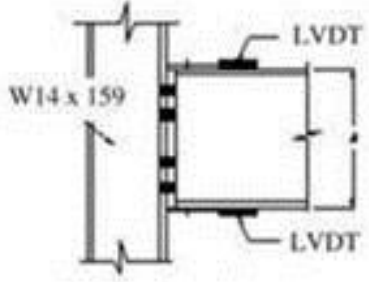

(c) Flush End Plate Connection

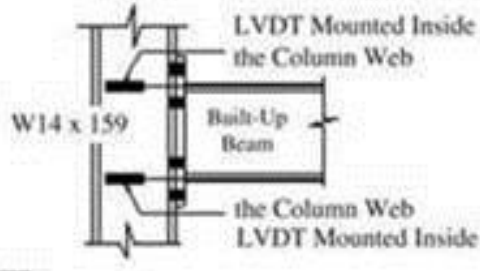

(d) Extended End Plate Connection

Figure 6. Typical Configuration of the Beam Column Connection Test Setup

The instrumentation consisted of two linear variable displacement transducers LVDTs to calculate the relative connection rotation and two wire potentiometers to measure displacements at two separate points along the beam specimen span. In addition, a load cell and displacement transducers were installed in the actuator to measure the cyclic load applied to the beam-end and the actuator stroke (displacement), respectively.

The LVDTs were placed directly above and below the top and bottom beam flanges for the double web angle and the flush end-plate connections (Figures $6 a$ and $6 c$ ). The locations of the DTs for the top and seat angle connection test specimens were directly above and below the outer edges of top and seat angle, respectively (Figure 6b). Finally, for the extended end-plate test specimens, the LVDTs were mounted in the column web to reach the centerlines of the top and bottom beam flanges by drilling two holes from back of the column flange (Figure 6d).

The relative displacements measured by the two LVDTs, divided by the vertical distance between their tips, was defined to be the local rotation of the connection. The global rotation of the connection was calculated by dividing the vertical displacement recorded by each wire potentiometer by the distance of the wire potentiometer from the face of the specimen column flange. Hence, the connection rotation at every load level was measured in three independent ways. The moment applied to the connection was calculated by multiplying the force recorded by the actuator load cell by the distance from the center of the actuator to the face of the column.

\section{Finite Element Modeling}

An accurate steel connection finite element model is a function of several parameters such as elements types, mesh sizes, material properties, and contact models. It also depends on the techniques for applying the boundary conditions, external loading, and pre-tensioning forces in the bolts. In this section the appropriate parameters and techniques for a precise connection model is presented. 
To validate the method, five nonlinear 3-D finite element models were developed to simulate the response of the beam-column connection under cyclic displacement control loading. The results obtained from the numerical analysis were compared with the results collected from the experimental testing to verify the accuracy of the numerical results. Elements types and mesh sizes are essential parameters for a precise simulation. In these connections, the steel plates were modeled using an 8-noded linear brick, reduced integration, and hourglass control (bricks C3D8R). A 6-noded linear triangular prism (C3D6) was also used to model the bolts, bolt head, nuts, and the washers. Initially the models were seeded using $1 / 2$ in $(12 \mathrm{~mm})$ spacing, and then the mesh was refined on critical locations to the desirable size (H-convergence). In the beam-column models, size of the mesh was gradually increased up to 6 in $(15.2 \mathrm{~cm})$ at the regions with significantly low strain. The option "seed by number" provided in ABAQUS 6-10.1 was used for simplicity and consistency. The details of the sizes and location of the meshes of the bolts are presented in Table 2 .

\begin{tabular}{lccc}
\hline Element & Line Number & $\begin{array}{c}\text { Number of } \\
\text { Seeds }\end{array}$ & Schematic \\
Washer & W1 & 20 & \\
& W2 & 15 & \\
Bolt & B1 & 15 & \\
& B2 & 10 & B1 \\
& B3 & 15 & \\
\hline
\end{tabular}

Table 2. The Mesh Size Distribution in the Bolts

A typical meshed bolt is presented in Figure 7. The linear triangular prism element (C3D6) is used for both the bolthead and the bolt-shank. The nut was modeled similar to the bolt-head and the extended length of the bolt was neglected. The nut, the bolt-head, and the bolt shank were considered as a single body. The bolt shank was modeled as a cylinder with a nominal diameter of the bolt. The washers were placed on both ends of the bolt (nut and bolt-head) to simulate experimental specimen. The length of the bolt was equal to the actual bolt length for each specimen. 


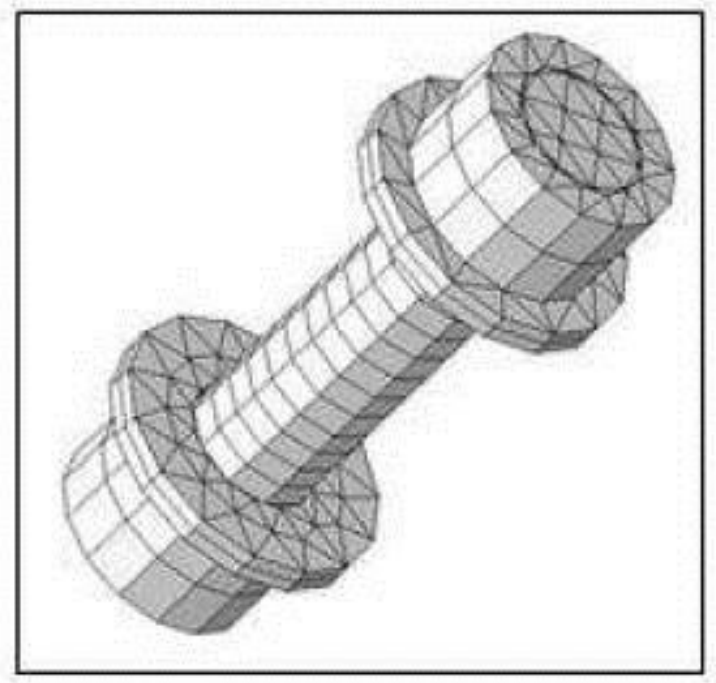

Figure 7. A Typical Bolt Mesh

Another key parameter is the number of layers of the mesh in the depth of the steel plates. Using less number of mesh layers may result in less accurate results; nevertheless, using more layers will increase the time of the computation. Based on the results of the study conducted by Bursi and Jaspart[11] [12] , the number of the layers of mesh in the modeling of the steel bolted connections, significantly affects the accuracy of the numerical results. The models were meshed in one, two, and three layers and the results were compared with experimental values, which led to acceptable results in the case of two layers. In addition, the best results were obtained from the models with a superior order, 8-noded, with the reduced integration (Zienkiewics [13]).

Bolt pre-tensioning is the first step of the connection loading which might be applied by means of applying initial force or initial displacement. In this study, the pre-tensioning bolt-force was modeled by applying an initial displacement to two parallel surfaces in the bolt-shank, using bolt-force with adjustments length function of the ABAQUS 6-10.1. The value of the initial displacement was adjusted by trial and error to achieve a sufficient pretensioning bolt-force specified by AISC design manual 2001[14]. The bolts were pre-tensioned in the first step and the displacement control loads are applied to the specimen during the next steps.

\subsection{Loading and Material Modeling}

Specimens were subjected to a cyclic displacement history in accordance with the FEMA [15] as shown in Figure 8. This was done by applying tip displacement to the beam. 


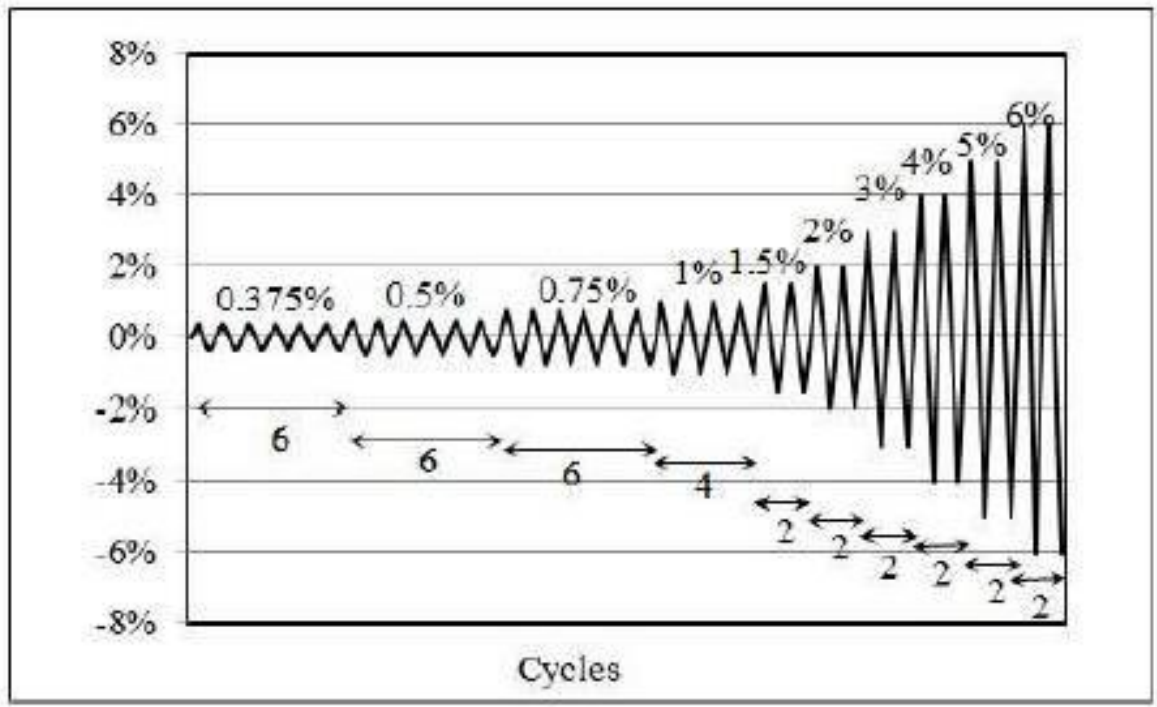

Figure 8. Cyclic Loading History, FEMA 350

The combined hardening plasticity model was used in order to model the material behavior during the cyclic loading. The parameters suggested by Kiamanesh et al. [16] and Ghobadi et al. [17] for combined strain hardening of Grade-50 hot-rolled steel was selected in the analysis algorithm. Isotropic hardening was used to model the material properties of the high strength steel bolts with material constitutive law as shown in Figure 9.

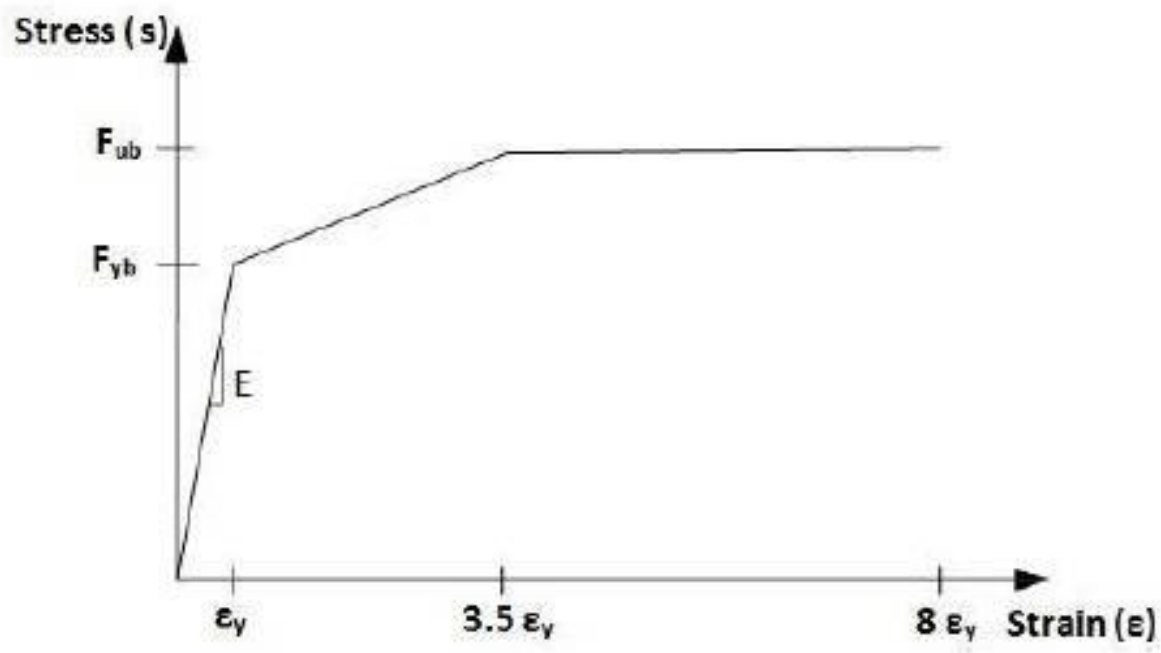

Figure 9. Stress-Strain Relationship for High Strength Bolts

The algorithm used for the combined hardening of the low-carbon material in ABAQUS 6.10-1 [18] was based on the study conducted by Doghri et al. [19], which is capable of performing both kinematic and isotropic hardening. The kinematic hardening parameters $\mathrm{C}$ and $\mathrm{y}$ are defined as the initial hardening modulus and the rate at which the hardening modulus increases with increasing plastic strain, respectively. 
The isotropic hardening behavior of the material is modeled with exponential law. The parameters $Q \infty$ and $b$ are defined as the maximum increase in the plastic range and the rate at which the maximum size is reached when plastic strain develops, respectively. The values of the combined strain hardening parameters used in this research are tabulated in Table 3.

\begin{tabular}{cc}
\hline Parameter & Value \\
\hline $\mathrm{C} \mathrm{ksi}(\mathrm{MPa})$ & $2030(14000)$ \\
$\gamma$ & 140 \\
$Q_{\text {. } k \text { si }(\mathrm{MPa})}$ & $261(1800)$ \\
$\mathrm{b}$ & 0.26 \\
\hline
\end{tabular}

Table 3. Material Properties

A Young's modulus of $E=30 \times 10^{3} \mathrm{ksi}(210 \mathrm{GPa})$ and a Poisson's ratio of $\mathrm{u}=0.3$ were used to define the elastic response of the material with $\mathrm{RyFy}=55 \mathrm{ksi}(385 \mathrm{MPa})$, where $\mathrm{Ry}=1.1$ is the ratio of expected yield stress to specified the minimum yield stress Fy.

\subsection{Contact Modeling}

The numerical results are highly sensitive to the contact properties between the components of the model. Contact algorithms should consider two physical constraints: i) penetration of one surface into another is prohibited and ii) since the surfaces are not glued together, the normal traction on surfaces could only be compression; in other words, no tension between contact pairs is allowed. In ABAQUS two contact pairs are called Master and Slave. The contact algorithm does not allow the Slave's nodes to penetrate in Master's surface.

Lagrange Multiplier Method and Penalty Method are two widely used algorithms for modeling the contact phenomenon.

In penalty method a comparatively large number (known as penalty coefficients) is defined in the formulation of the total potential function that enforces the constraints to be satisfied. This number should be selected carefully because for very small values it does not guarantee the constraint to be satisfied (either penetration or tensile traction may occur) and for very large values, it causes ill conditioning of the system's equations and may cause the solution not to converge.

The Lagrange Multiplier Method does not require contact stiffness; instead it requires chattering control parameters by assuming that the contact status remains unchanged. If the contact status from the previous iteration is open and the current calculated penetration is smaller than the maximum allowable penetration, then contact remains open. Otherwise the contact status switches to closed and the next iteration is processed. Lagrange multiplier method adds additional degrees of freedom to a FEM model and requires additional iterations to stabilize contact conditions. This will increase the computational cost and may even lead to solution divergence if many contact points are oscillating between sticking and sliding during iterations.

Augmentation iteration can be used within the penalty algorithm to reduce the magnitude of penetration. In this case the algorithm is called Augmented Lagrange method. This method can be used only on hard contacts in which 


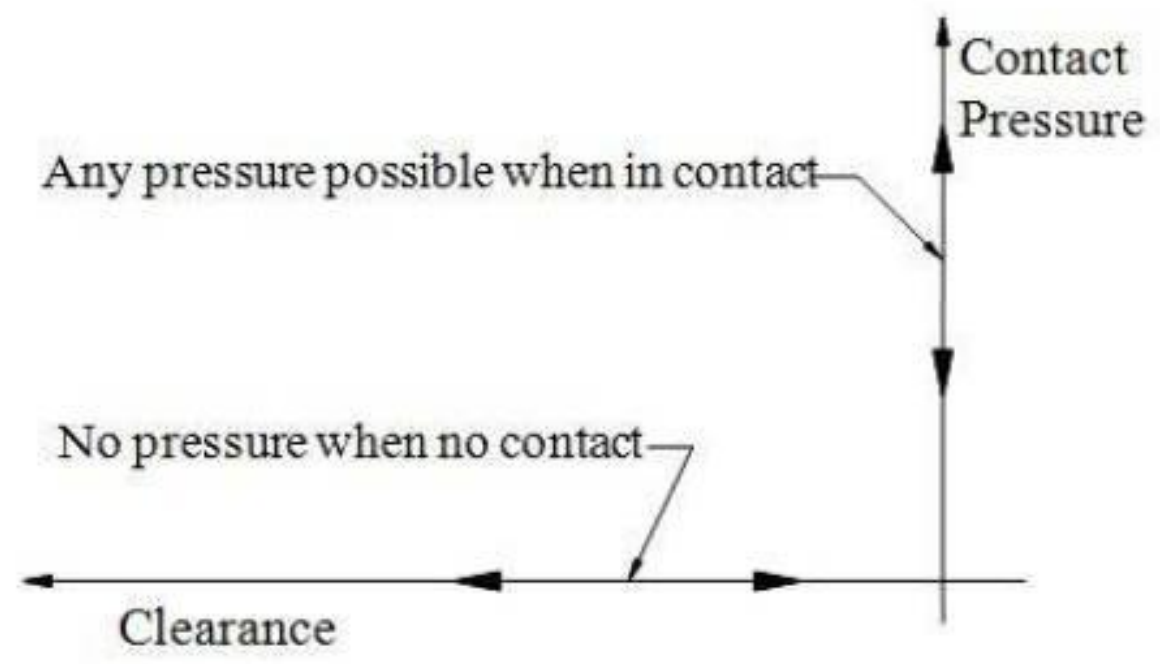

Figure 10. Hard Contact Pressure-Overclosure Relationship

Although Augmented Lagrange method increases the number of iterations, it makes the resolution easier by controlling the magnitude of penetration [18].

In bolted connections with slip critical bolts, the force and partial moments are transferred from beam to column by normal and frictional actions.

Small sliding surface-to-surface was considered for all the contacts. The welds were assumed to be rigid and modeled by tie-contact algorithm which constrains the transitional degrees of freedom between contact pairs. No rotational degrees of freedom are constrained in this algorithm. The frictional surfaces accompanied by tangential force were modeled by tangential-contact algorithm. The surface contact between the end-plate and column was modeled by frictional contact using penalty stiffness with the penalty value of 0.2 . The surfaces with normal force were modeled using Augmented Lagrange Formulation [18]. The tangential contact between the bolt-hole and the bolt shank was considered to be frictionless. Also, hard contact was used for the connection between bolthead/nuts to the end-plate/column flange.

Master surfaces of the contacts pair represent the surface of column flange, bolt-head, bolt-shank, washer, whereas the slave surface is defined as the surface interfacing with the master surface. The master surface in general should have finer mesh.

\section{Results and Discussion}

\subsection{Extended End-Plate Connection}

A typical 3-D finite element model of the extended end-plate connection is presented in Figure 11. A W16x67 hotrolled cantilever beam was connected to a W14x159 column using an extended end-plate and eight high strength 
bolts. The cyclic displacement control load is applied to the tip of the beam.

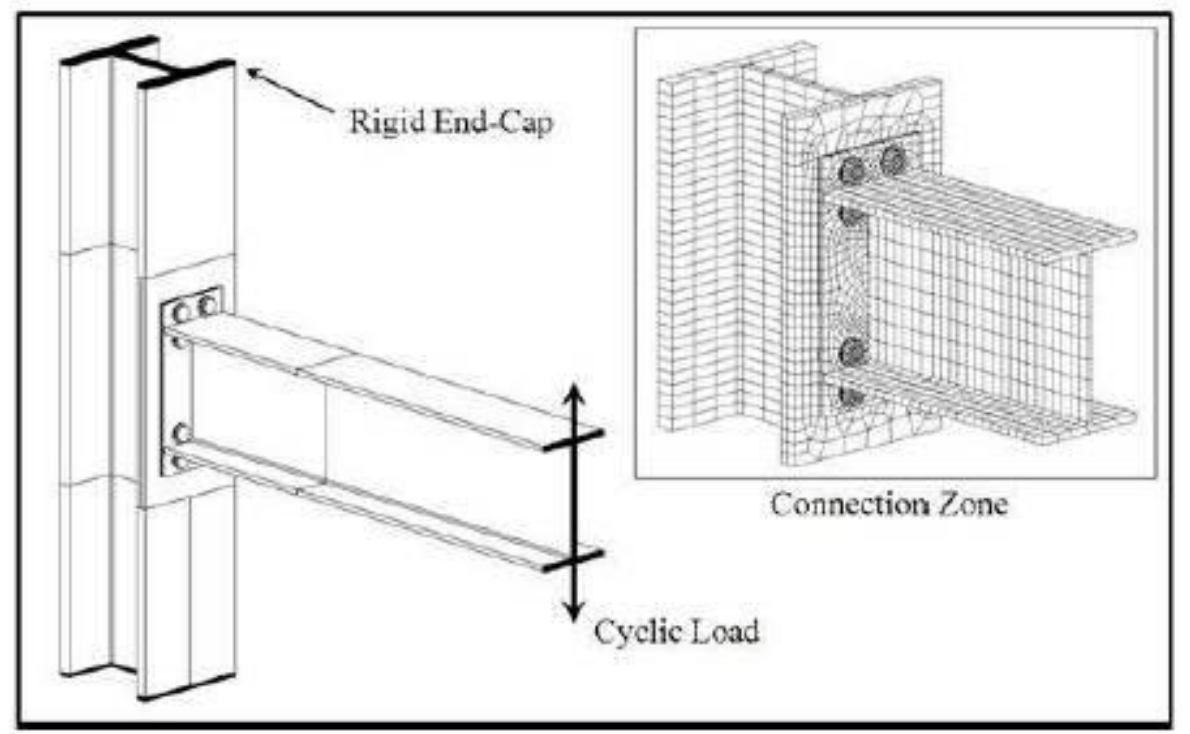

Figure 11. Extended End-Plate Finite Element Model, and Mesh Properties

Figure 12 shows the comparison of the moment-rotation hysteresis obtained from finite element analysis with those from full-scale experimental tests. A close examination between the two plots shows FEM is highly capable of predicting the connection response. Particularly, the numerical results closely follow the loading and unloading stiffness of the connection during each cycle. There is a 3.5\% difference between areas under the outer hysteresis loops of FEM and experimental.

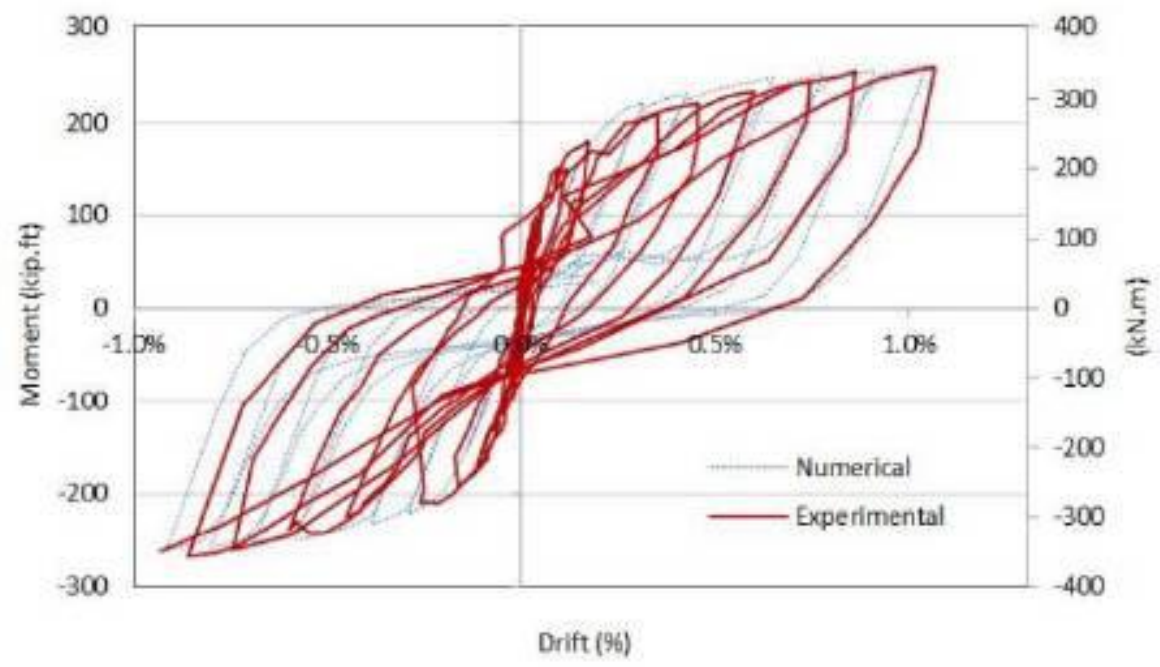

Figure 12. Comparison FEM and Experimental Hysteresis for Extended End-Plate Connections

Experimental data showed that the bolt-failure was the failure mode for this connection which is also confirmed in this study as shown in Figure 13. 


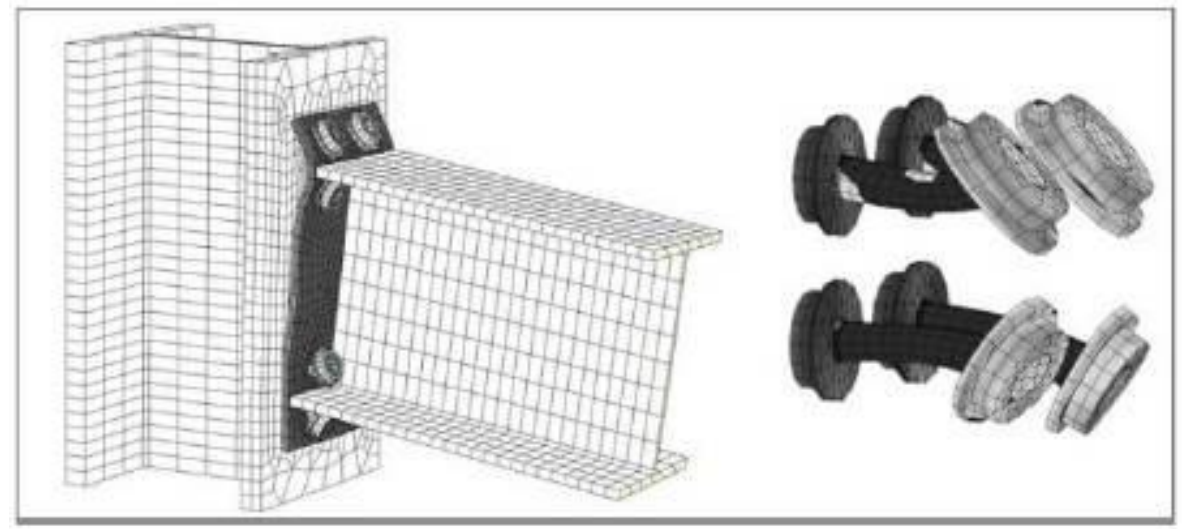

Figure 13. Failure of Bolts in the Extended End-Plate Connection

\subsection{Top-and-Seat Angle Connection}

To model the behavior of the top-and-seat connection under cyclic loading, a hot-rolled W16x67 cantilever beam is connected to a hot-rolled W14x159 column using two $6 \times 6 \times 3 / 4$ angles. This finite element model is validated with the experimental results as shown in Figure 14. The hysteresis results illustrated in Figure 15 which shows the correlation between the moment-curvature curves obtained from experimental testing and finite element analysis. The FEM basically follows experimental hysteresis loops closely. The difference between areas under the outer loops of hysteresis loops obtained from experiment and FEM is $11.5 \%$.

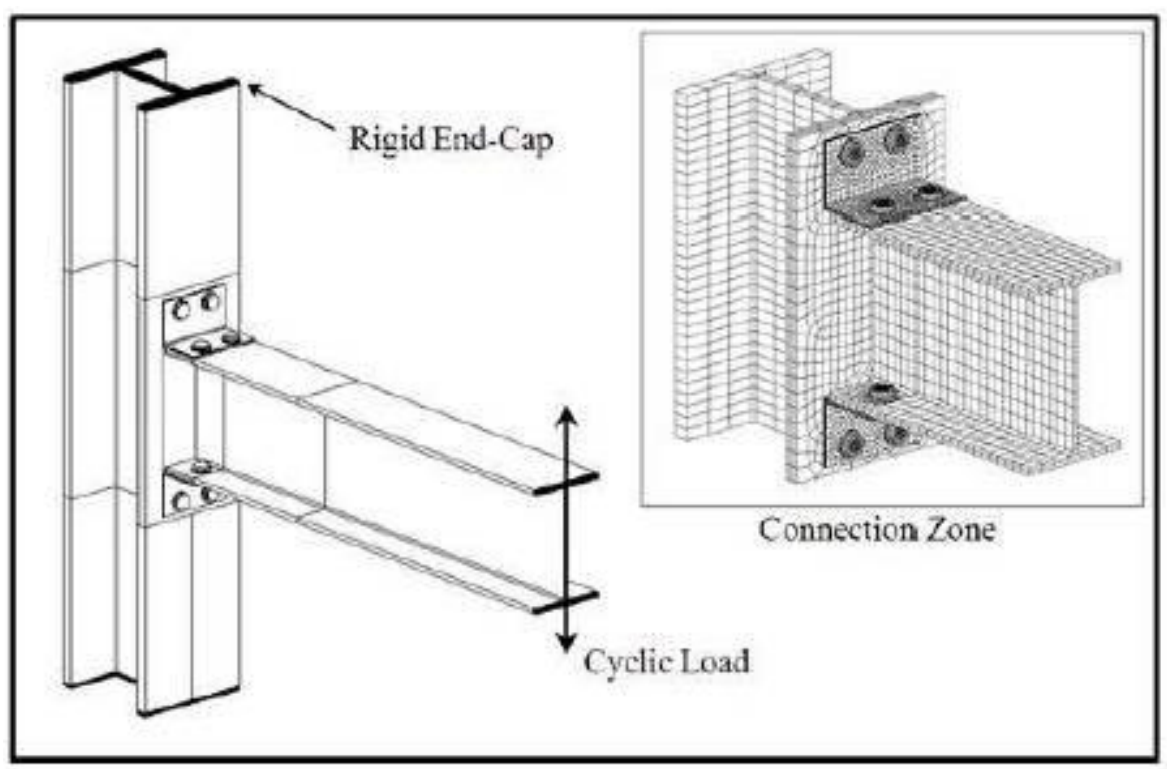

Figure 14. Top-and-Seat Angle Connection Finite Element Model, and Mesh Properties 


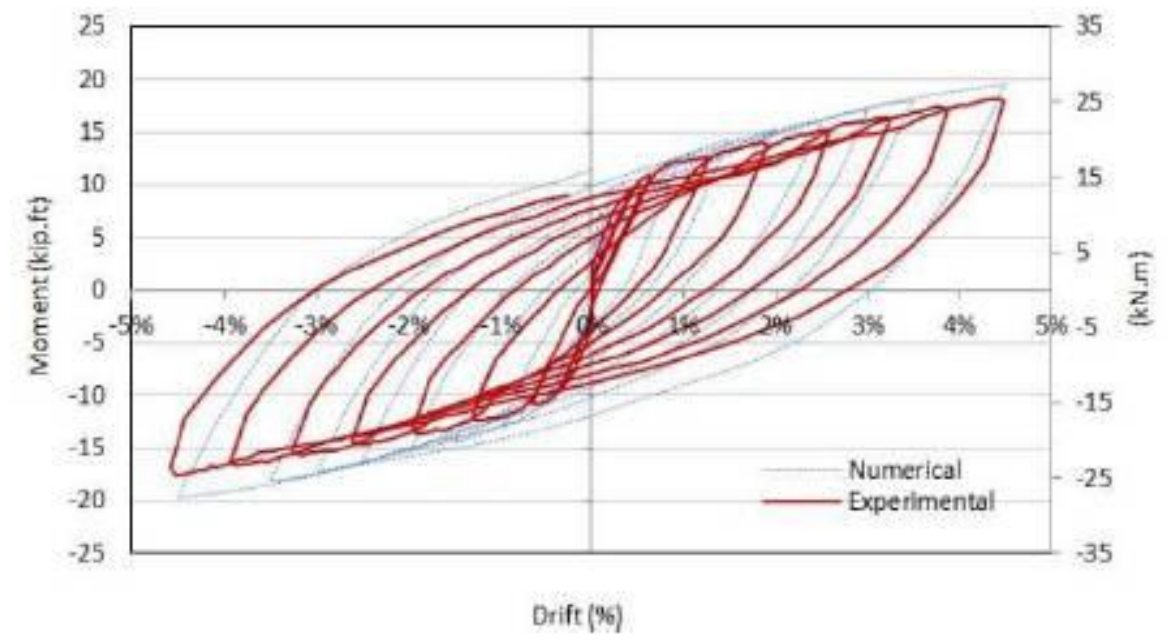

Figure 15. Comparison of FEM and Experimental hysteresis for Top-and-seat angle connection

The test specimens were designed such that the bold and weld fracture were prevented. Thus, the failure was defined by excessive rotation whose value was typically 0.045 radians. Accordingly, no bolt failure is observed in the results from Finite Element Analysis before the rotation of 0.04 radians is reached.

\subsection{Bolted/bolted double web angle connection}

To model the behavior of the bolted/bolted double web angle connection under cyclic loading, a hot-rolled W24x104 cantilever beam is connected to a hot-rolled W14x159 column. This test specimen was bolted to both the beam web and the column flange using two 15 in $L 5 x 5 x^{3} / 4$ on both side of the web, as shown in Figure 16 . This FEM is validated with the experimental results in Figure 17. The hysteresis results illustrated in Figure 17 shows a close correlation between the moment-curvature curves obtained from experimental testing and finite element analysis. The percentage difference between the hysteresis loops obtained from FEM and experimental is $16 \%$.

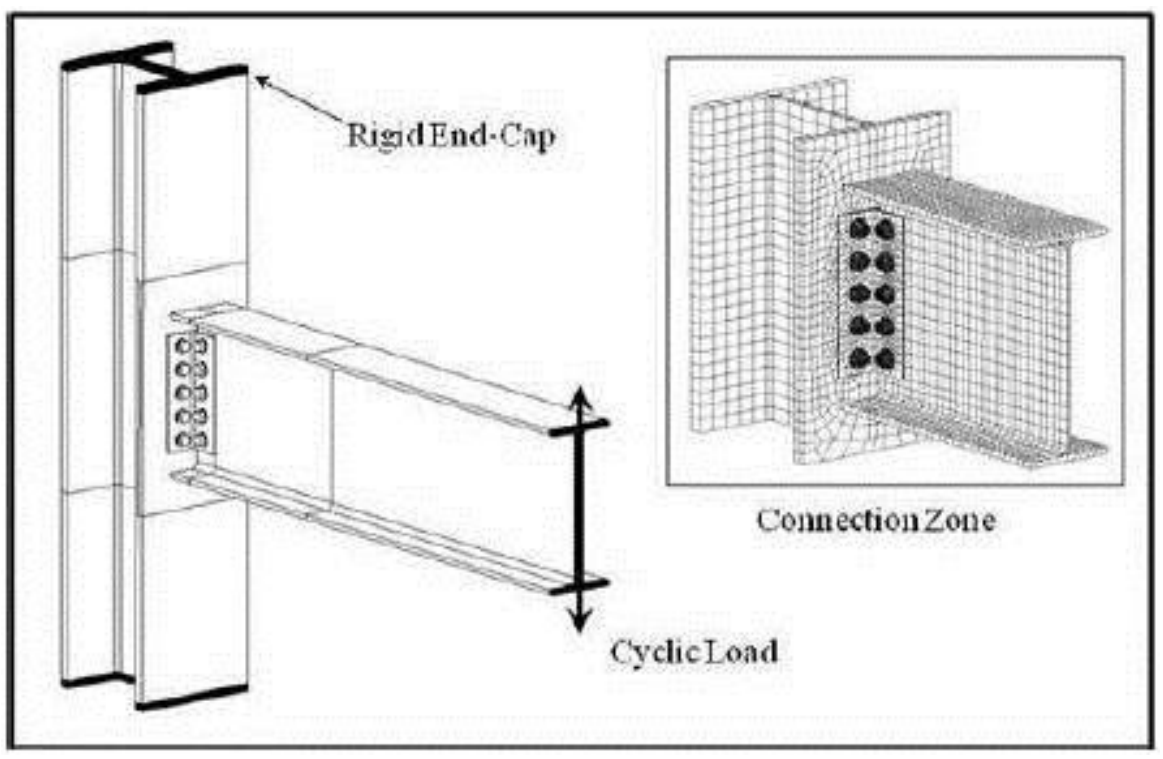


Figure 16. Bolted/bolted Double Web Angle Connection Finite Element Model, and Mesh Properties

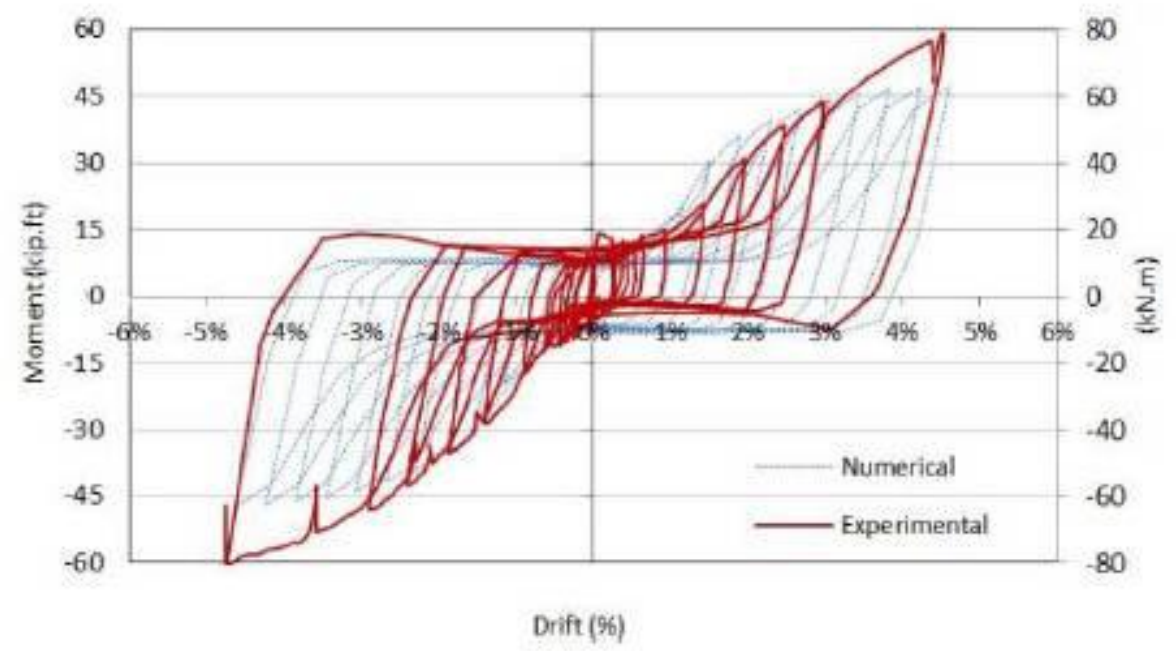

Figure 17. Comparison of FEM and Experimental Hysteresis for Bolted/bolted Double Web Angle Connection

(Abolmaali et al. [1]) discussed about the formation of a flat region in the hysteresis loop of the bolted/bolted double web angle connections. This flat region is presented in Figure 17. This behavior is due to elongation of the beam web's bolt-holes (change in geometrical configuration of bolt holes from circular to oval shape), which causes the bolts to move freely in the bolt-holes during load reversal. The connection zone of the beam-web of this connection is presented in Figure 18, which shows that the bolt-holes undergo a large plastic deformation. This explains the sudden reduction of the stiffness in the connection during the cyclic loading.

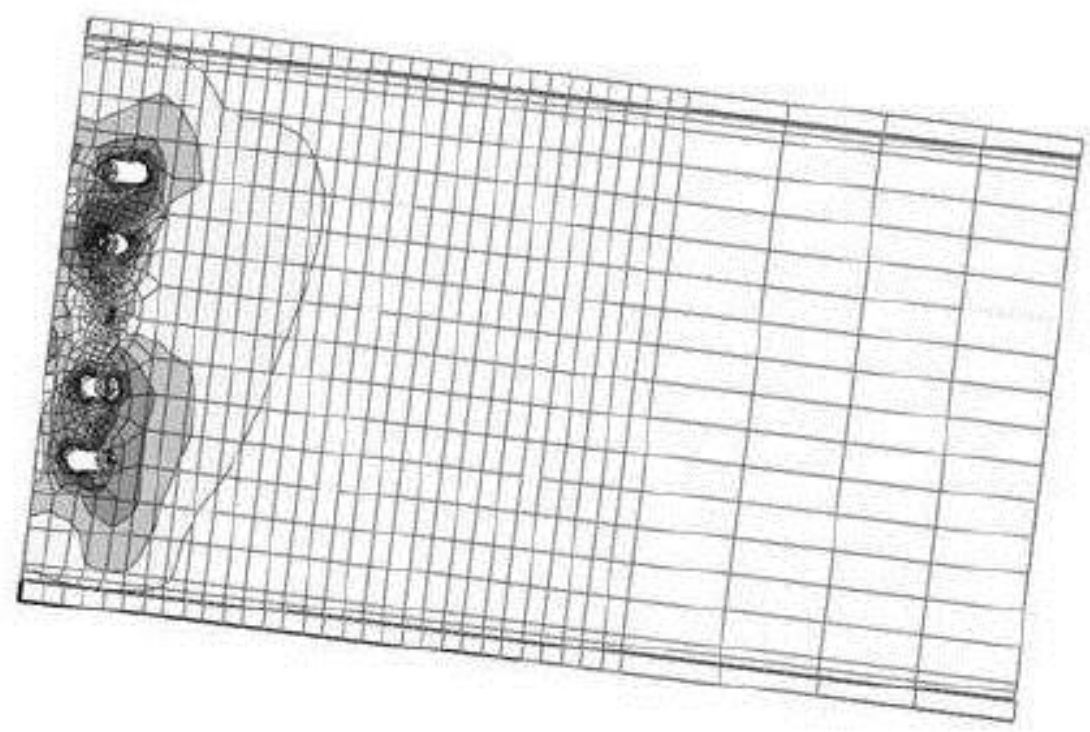

Figure 18. Deformation of the Bolt-Holes from Round to Oval Due to Excessive Elongation Inolted/bolted Double 


\subsection{Welded-bolted double web angle connection}

A 3-D finite element model of the welded-bolted double web angle connection is presented in Figure 19. A W24x104 hot-rolled cantilever beam is connected to a W14x159 column using two 15 in L5x $5 \times 3 / 4$ angle on both side of the web. The angles are welded to the beam-web and bolted to the column flange using eight $3 / 4 \mathrm{in} \mathrm{(19} \mathrm{mm}$ ) diameter high strength bolts.

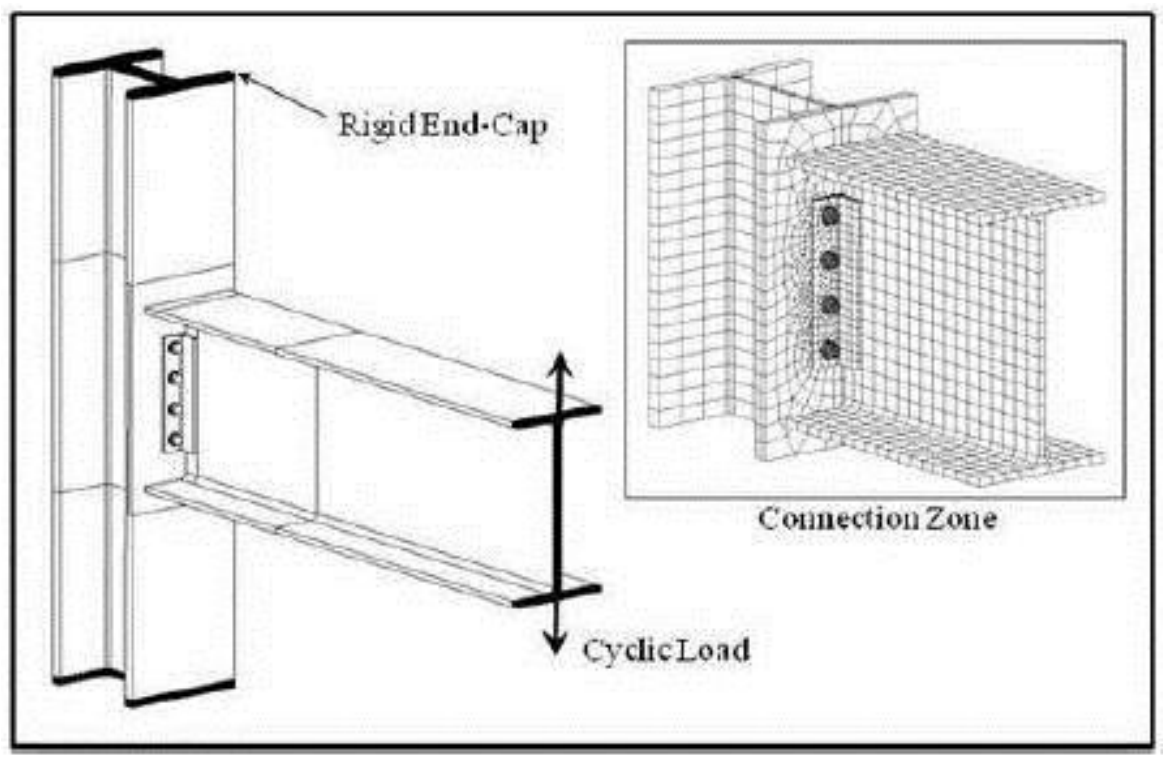

Figure 19. Welded-bolted Double Web Angle Finite Element Model

Figure 20 shows the comparison of the moment-rotation hysteresis loops obtained from the FEM with the experimental test. This figure also shows close relationship between both hysteresis loops. The difference between the area under outer loops of FEM and experimental is $9.3 \%$.

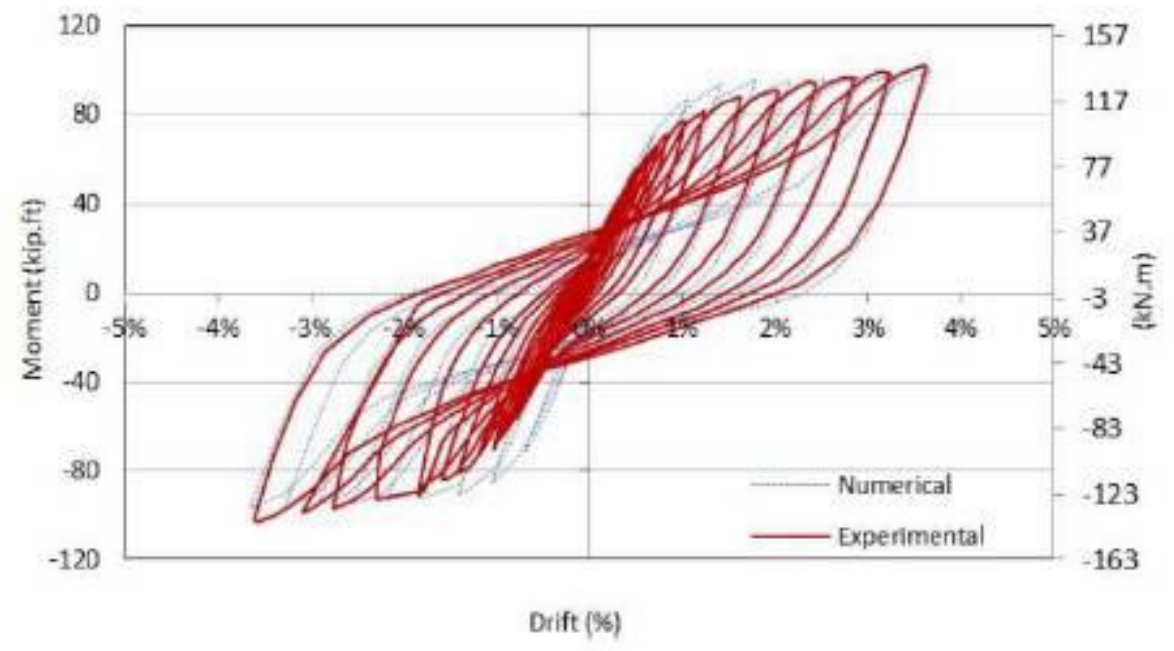


Figure 20. Comparison of FEM with Experimental Hysteresis for Welded-bolted Double Web Angle Connection

Further investigation conducted by Abolmaali et al. [1] indicates that this model is failed due to excessive yielding of the angles. Same failure mode was observed during the finite element analysis as shown in Figure 21 . During FEM analysis, the strains in bolts did not exceed the bolts ultimate strain until the experimental ultimate rotation was reached. This verifies that the FEM simulates the experimental behavior.
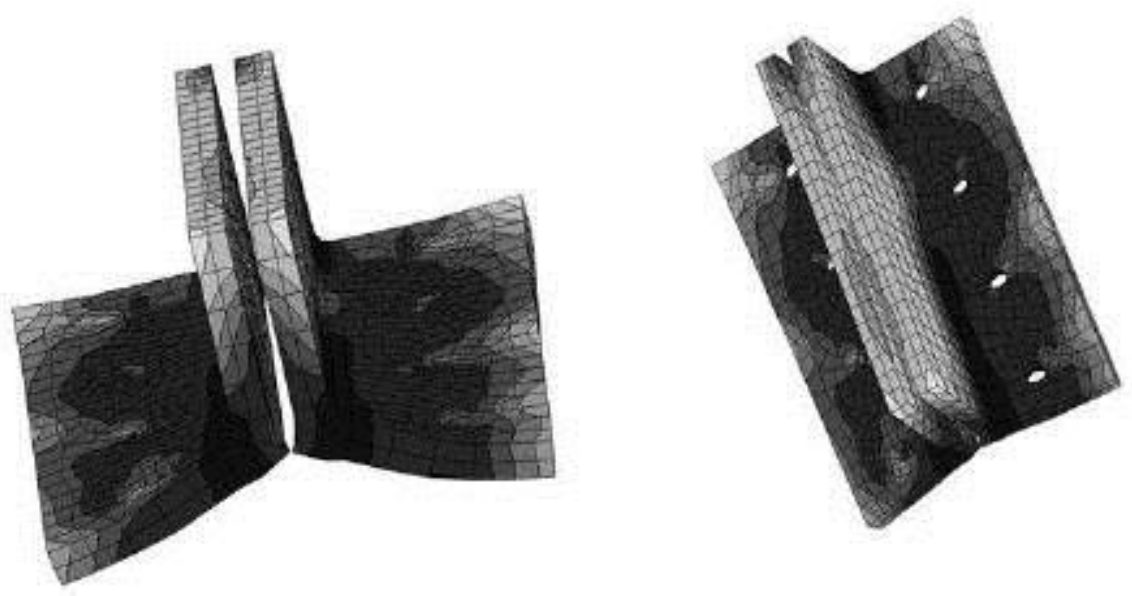

Figure 21. Failure of the Angle Due to Excessive Elongation in Welded-bolted Double Web Angle Connection

\subsection{Flush end-plate connections}

A 3-D finite element model of the flush end-plate connection is presented in Figure 22. A W18x46 hot-rolled cantilever beam is connected to a W14×159 column using a 3/8 in flush end-pate and eight $3 / 4$ in high strength bolts.

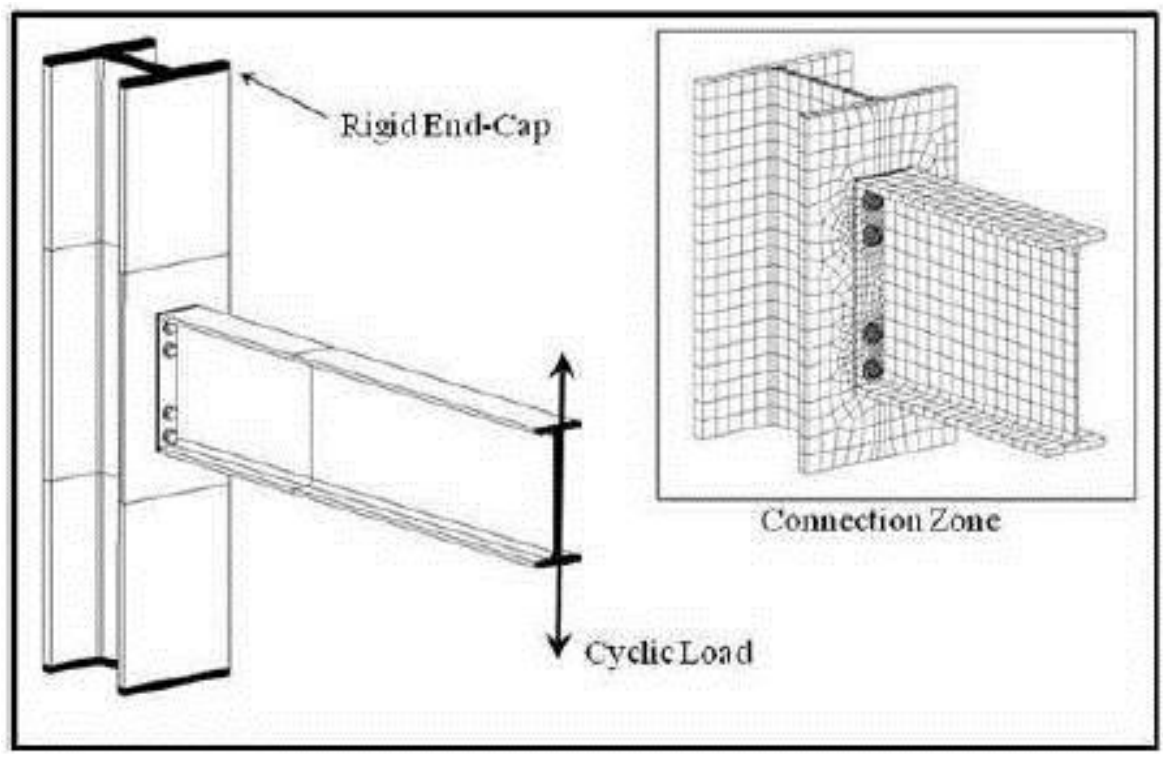


Figure 22. Flush End-Plate Connection Finite Element Model, and Mesh Properties

Figure 23 shows the results of the experimental test conducted on flush end-plate connection. Also, the results of the applied moment versus the rotation of the end-plate of the same connection obtained from the numerical analysis are presented in this figure. A close examination of the results shows a satisfactory agreement between numerical and experimental results. The difference between outer areas of hysteresis loops of numerical and experimental results is $5.6 \%$.

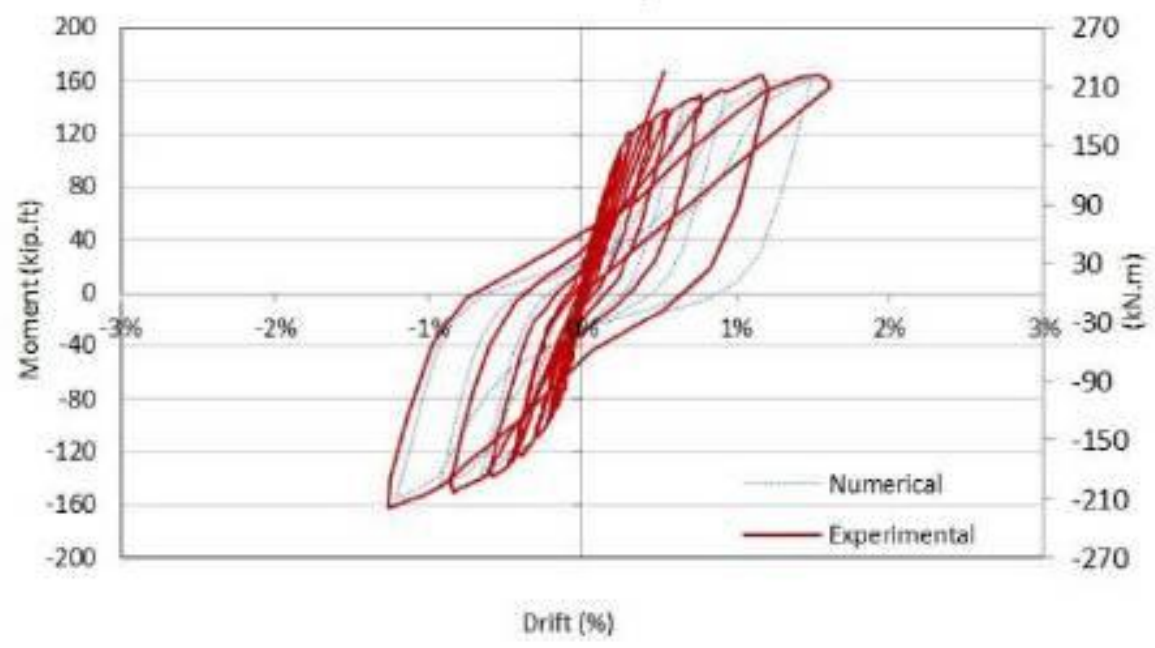

Figure 23. Comparison of FEM with Experimental Hysteresis Loops for Extended End-Plate Connections

\section{Conclusion}

The simulation of semi-rigid steel connections by means of nonlinear three-dimensional finite element method have been presented. Modeling of material properties, element types, meshing size, contact properties between different components, friction, and clamping forces due to pre-tensioning for 5 semi-rigid connections have been described in details.

The results of this study showed excellent agreement between the moment-rotation hysteresis loops obtained from the FEM analysis and those obtained from experimental tests for all five types of semi-rigid connections. This includes the prediction of initial stiffness, unloading stiffness, and particularly the failure modes associated with each connection assembly. The energy dissipation characteristics of connection were measured by the area under the outer loop of the moment-rotation hysteresis loops. The accuracy of the simulation capabilities presented here showed differences in the range of 3.5 and 16 percent when FEM and experimental results were compared for energy dissipation. The average difference was $9.2 \%$.

In conclusion, results of this study confirmed that the moment rotation hysteresis behavior of the steel connections might be quite well predicted by using an accurate 3D non-linear finite element analysis.

\section{References}

[1]. A. Abolmaali, A.R. Kukreti and H. Razavi, (2003). “Hysteresis behavior of semi-rigid double web angle steel 
connections", Journal of Constructional Steel Research 59, pp. 1057-1082.

[2]. Krishnamurthy, N., and Graddy, D.E. (1976). "Correlation between 2- and 3- Dimensional Finite Element Analysis of Steel Bolted End-Plate Connections," Computer and Structures, Pergamon, 6(4-5/6), 381-389.

[3]. Krishnamurthy, N., Huang H. T., Jefferey P.K., and Avery L.K. (1979). "Analytical M- $\theta$ Curve for End-Plate Connections," Journal of Structural Division, 105(ST1), 133-145.

[4]. Krishnamurthy, N. (1980). "Modeling and Prediction of Steel Bolted Connection Behavior," Computer and Structure, 11, 75-82.

[5]. Kukreti, A.R., Ghassemieh, M., and Murry, T.M. (1990). "Behavior and Design of Large-Capacity Moment End Plates," Journal of Structural Engineering, ASCE, 116(3), 809-828.

[6]. Kukreti, A.R., Biswas P. (1997). "Finite element analysis to predict the cyclic hysteretic behavior and failure of end-plate connections", Journal of Computers and Structures 65(1):127-47.

[7]. Ahmed, A., Kishi, N., Matsuoka, K., and Komuro M. (2001). "Nonlinear Analysis on Prying of Top-and Seat-Angle connections", Journal of Applied Mechanics, 4:227-36.

[8]. Popov, E.P., and Takhirov, S.M. (2002). "Bolted Large Seismic Steel Beam-to-Column Connections", Part 1:

Experimental Study, Engineering Structures, Journal of Earthquake, Wind and Ocean Engineering, Vol. 24, Issue 12, 1523-1534: Elsevier Science Ltd.

[9]. Nie J, Cai CS, Wu H, Fan JS. (2006). "Experimental and theoretical study of steel-concrete composite beams with openings in concrete flange", Journal of Engineering Structures, 28(7): 992-1000.

[10]. Abolmaali, A., Kukreti, A., Motahari, A., \& Ghsemieh, M, (2009). "Energy Dissipation Characteristics of SemiRigid Connections," Journal of Constructional Steel Research, Volume 65, Issue 5, May Pages 1187-1197

[11]. Bursi, O. S., Jaspart, J. P., (1997). "Benchmark for Finite Element Modeling of Bolted Steel Connections," Construction Steel Research, 43, 17-42

[12]. Bursi, O.S., \& Jaspart, J.P., (1998). "Basic Issues in the Finite Element Simulation of Extended End-Plate

Connections," Computers and Structures, 69, 361-382

[13]. Zienkiewics, O., \& Taylor, R. L. (1989). "The Finite Element Methods," 4th ed., Maidenhead: McGraw-Hill.

[14]. American Institute of Steel Construction, (2001). Manual of Steel Construction Load and Resistance factor

Design, 3rd ed. Chicago, IL, 2001.

[15]. FEMA recommended seismic design criteria new steel moment frame building, Report no. FEMA-350.Federal Emergency Management Agency; 2000.

[16]. Kiamanesh, R., Abolmaali, A., and Ghammemieh M. (2010). "The Effect of Stiffeners on the Strain Patterns of the Welded Connection Zone", Journal of Constructional Steel Research, 66(1), 19-27.

[17]. Ghobadi, M.S., Mazroi, A., \& Ghassemieh, M. (2008). “Cyclic Response Characteristics of Retrofitted Moment Resisting Connection", Journal of Constructional Steel Research, 65(3):

[18]. ABAQUS Version 6.8-2 User's Manual, Hibbit, Carlson \&Sorensen Inc., Michigan; 2008.

[19]. Doghri, I., Benallal, A., \& Billardon, R. (1988). "An Integration Algorithm and the Corresponding Consistent Tangent Operator for Fully Coupled Elastoplastic and Damage Equations", Communications in Applied Numerical Methods, (4):731-40

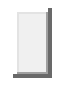

